\title{
A Multi-Scenario Optimization Model for Emergency Cold Chain Logistics Distribution
}

\author{
Yile Ba $\mathbb{D},{ }^{1}$ Chenxi Feng $\mathbb{D},{ }^{2}$ Wenpeng Jia $\mathbb{D}^{1},{ }^{1}$ Xin Liu $\mathbb{D},{ }^{1}$ and Jianwei Ren $\mathbb{D}^{2}$ \\ ${ }^{1}$ School of Economic and Management, Beijing University of Chemical Technology, Beijing 100029, China \\ ${ }^{2}$ Transportation Institute, Inner Mongolia University, Hohhot 010070, China \\ Correspondence should be addressed to Jianwei Ren; renjianwei309@126.com
}

Received 27 August 2021; Revised 19 November 2021; Accepted 10 December 2021; Published 24 December 2021

Academic Editor: Rohit Salgotra

Copyright ( 2021 Yile Ba et al. This is an open access article distributed under the Creative Commons Attribution License, which permits unrestricted use, distribution, and reproduction in any medium, provided the original work is properly cited.

Cold chain logistics has been playing a more and more crucial role in modern society. As a special professional cold chain logistics, emergency cold chain logistics can provide quality assurance for temperature-sensitive products in emergency situations. Due to the fact that demand is uncertain in emergency situations, the cold chain logistics companies have to deal with the issue of uncertainty. However, there is no literature on the emergency cold chain logistics distribution optimization problem with uncertain demand. This research contributes to solving this problem. To deal with uncertain demand in emergency situations, an emergency cold chain logistics distribution optimization model with time windows is proposed based on scenario analysis. The objectives of the model are to minimize the total cost and shorten the delivery time simultaneously. The model can also optimize product procurement and refrigerated vehicle renting. The multi-scenario optimization model is applied to a Chinese cold chain logistics center to verify its effectiveness.

\section{Introduction}

Cold chain logistics is the technology and process that allows for the safe transport of temperature-sensitive goods and products along the supply chain $[1,2]$. Cold chain logistics has been becoming a more and more crucial role in modern society [3]. The global cold chain market size was valued at 233.8 billion USD in 2020 and is expected to reach 340.3 billion USD by 2025 , registering a CAGR (compound annual growth rate) of $7.8 \%$ from 2021 to 2025 [4]. The North America cold chain market was valued at 59.1 billion USD, which was the largest region in 2020. The Asia-Pacific region cold chain market was estimated to witness the fastest growth from 2021 to 2025 [5].

As a special professional cold chain logistics, emergency cold chain logistics can provide quality assurance for temperature-sensitive products in emergency situations [6]. Emergency cold chain logistics plays an essential role in dealing with emergencies. For example, the cold chain logistics industry plays a crucial role in the prevention and control of Coronavirus Disease 2019 (COVID-19). The cold chain logistics companies must not only kill the coronaviruses on packages but also cope with uncertain demand. Demand is uncertain in emergency situations, which means that there are not enough historical data to estimate uncertain demand. However, there is no literature on the emergency cold chain logistics distribution optimization model to deal with uncertain demand. This paper will propose a multi-scenario optimization model to help managers distribute temperature-sensitive products under emergency situations more effectively.

The innovations and contributions of this paper are as follows:

(1) As far as we know, this is the first study to propose a multi-scenario optimization model for cold chain logistics distribution dealing with uncertain demand in emergency situations. 
(2) The scenario-based multi-objective optimization model aims at minimizing the total cost and shortening the delivery time simultaneously.

(3) The proposed method can also optimize product procurement and refrigerated vehicle renting. Therefore, our model is more in line with the actual operation.

(4) A Chinese cold chain logistics system is studied to validate the effectiveness of the proposed model.

This paper is structured as follows. In Section 2, the literature is reviewed, and the problem of the emergency cold chain logistics distribution optimization is described. The multi-scenario optimization model with time windows is developed in Section 3. In Section 4, the multi-scenario optimization model is applied to a Chinese cold chain logistics center to verify its effectiveness. The main conclusions are summarized in Section 5.

\section{Literature Review and Problem Description}

The research on the optimization methods for cold chain logistics distribution is a hot topic. The objectives of most models in the literature are to minimize total cost. Zhang and $\mathrm{Qu}$ studied an optimization model to reduce the total cost of cold chain logistics distribution, including transportation cost, storage cost, and damage cost. They presented an improved genetic algorithm to tackle the proposed model [7]. Fan et al. established an optimization model to minimize the total cost of cold chain logistics and developed an ant colony algorithm to solve it [8]. Li et al. constructed an optimization model and developed an improved tabu search algorithm to solve their model. They considered the cost of energy, carbon emissions, and vehicle leasing simultaneously [9]. Pan established a cold chain logistics vehicle path model, considering carbon emissions cost and the usage cost of the Internet of Things (IoT). The model was solved by using the wolf colony algorithm principle and the ant colony algorithm [10]. Liu et al. presented a low-carbon cold chain logistics distribution model, considering penalty cost, carbon emission cost, distribution cost, damage cost, and refrigeration cost. They proposed an improved genetic algorithm to tackle the model [11].

In addition to minimizing the total cost, it is also important to shorten the delivery time in the emergency cold chain logistics distribution. However, the above researches did not consider this important factor. Ma et al. proposed an optimization model to minimize the total cost of cold chain logistics distribution, taking time windows into account [12]. Osvald and Stirn studied the distribution of fresh vegetables and developed a tabu algorithm to solve their mathematical model with time windows [13]. Zou et al. proposed an optimization model whose objective was to minimize the time of cold chain logistics [14]. Wang et al. proposed a cold chain logistics optimization model considering time windows. To tackle the model, they developed a cycle evolutionary genetic algorithm [15]. Zhang et al. proposed an optimization model for cold chain logistics distribution, considering time windows. They developed a genetic algorithm to tackle the model [16]. To cope with the trade-off between minimizing the total cost and maintaining the quality, Nakandala et al. proposed a multi-product food transportation cost function that defined the total cost as the sum of transportation cost, cooling cost, and devalued cost [17]. Theophilus et al. presented a mixed-integer optimization model for the truck scheduling at cold chain crossdocking terminals (CDT). This model can capture the decay of perishable products using an exponential function throughout the service of arriving trucks [18]. Tsang et al. proposed a dynamic multi-temperature transportation management system, considering Internet of Things (IoT) technologies, multi-objective optimization, and fuzzy logic. The multiple objectives include minimizing the travel time, minimizing the number of vehicles used for the delivery, and maximizing customer satisfaction [19]. However, these studies did not consider the uncertainty of demand.

Because demand is uncertain in emergency situations, this research will develop an optimization model for the emergency cold chain logistics distribution considering uncertain demand. The problem of the optimization of emergency cold chain logistics distribution can be described as follows: (1) To meet uncertain demand in emergency situations, how to dispatch several kinds of products from cold chain logistics centers to their customers by using refrigerated vehicles within time windows? (2) If the logistics service provider does not have enough refrigerated vehicles, how many refrigerated vehicles should be rented? (3) If there are not enough products available, how many products should be purchased? (4) Because the optimization plan should minimize both the total cost and the total delivery time, the optimization model should have two objectives. We aim to deal with uncertain demand in emergency situations, so this research provides distribution plans before orders are placed rather than after the demand has been put forward.

Some assumptions should be pointed out to develop the optimization model for the emergency cold chain logistics distribution:

(1) There is only one cold chain logistics center whose location is certain.

(2) There are many customers and their locations are known, but their demand is uncertain in emergency situations. If the logistics service provider fails to fulfill or exceeds the uncertain demand, it is necessary to pay the penalty cost.

(3) There is only one kind of refrigerated vehicle. If there are not enough vehicles, the logistics service provider should rent vehicles whose rental fees are known.

(4) Both the departure and destination of the refrigerated delivery vehicles are the cold chain logistics center. The driving speed of refrigerated delivery 
vehicles is known. Each customer can only have one refrigerated vehicle for products delivery while each refrigerated vehicle can provide service for multiple customers.

(5) There are several kinds of products that can be loaded in the same vehicle. If the available products are not enough to meet demand, the logistics service provider should purchase products. The prices of these products are known.

\section{Methodology}

3.1. Mathematical Model. To cope with uncertain demand, which means that there are not enough historical data to estimate uncertain demand, a multi-scenario optimization model for emergency cold chain logistics is developed by using scenario analysis [20-22]. In fact, uncertainty has been studied by numerous scholars from several disciplinary perspectives. However, the traditional methods, e.g., the stochastic theory and the fuzzy theory, cannot be used to deal with such uncertain parameters $[23,24]$. The method of scenario analysis deals with such uncertain parameters by generating a set of scenarios $[25,26]$. Tables $1 \sim 3$ show the symbols used in the proposed Table 2 model.

3.1.1. Objective Functions. A multi-objective optimization model is needed to be proposed to aid the distribution of temperature-sensitive products at minimal total cost and an acceptable level of the quality of products.

In order to preserve the quality of temperature-sensitive products, the products should be transported to customers in the shortest time. The objective function set (1) minimizes the expected delivery time including the transport time, the waiting time, and the service time.

$$
\min f=\sum_{s \in S} W_{S}\left(\sum_{i \in N} \sum_{j \in N} \sum_{k \in K} v_{i j k}^{s} k_{i j k}^{s}+\sum_{i \in N} \sum_{j \in N^{\prime}} \sum_{k \in K} v_{i j k}^{s} w_{j k}^{s}+\sum_{i \in N} \sum_{k \in K} v_{i j k}^{s} f_{j k}\right)
$$

The objective function set (2) minimizes the expected total cost. The main cost components are considered in the model, including the fixed cost of refrigerated vehicles, transportation cost, the rental fee of refrigerated vehicles, the cost of products purchased, and the penalty cost of failing to fulfill or exceeding demand.

$$
\min c=\sum_{s \in S} w_{s}\left(\sum_{j \in N^{\prime}} \sum_{k \in K} C_{k} v_{0 j k}^{s}+\sum_{i \in N} \sum_{j \in N} \sum_{k \in K} B d_{i j} v_{i j k}^{s}+R H^{s}+\sum_{p \in P} C_{P} H_{P}^{s}+\sum_{j \in J^{\prime}} \sum_{p \in P} C_{j p}\left|U_{j p}^{s}\right|\right) .
$$

3.1.2. Constraint Sets. The constraint set (3) ensures that only one refrigerated vehicle can arrive at the customer $j$ in the scenario $s$, while the constraint set (4) ensures that only one refrigerated vehicle can leave the customer $j$ in the scenario $s$. The two constraint sets ensure that each refrigerated vehicle can serve many customers while each customer may be served by only one refrigerated vehicle.

$$
\begin{aligned}
& \sum_{i \in N} \sum_{k \in K} v_{i j k}^{s}=1, \quad \forall j \in N^{\prime}, \forall s \in S, \\
& \sum_{i \in N} \sum_{k \in K} v_{j i k}^{s}=1, \quad \forall j \in N^{\prime}, \forall s \in S .
\end{aligned}
$$

The constraint sets (5) and (6) guarantee that the refrigerated vehicle $k$ should start and stop at the cold chain logistics center and cannot turn back halfway in the scenario $s$.

$$
\begin{aligned}
\sum_{j \in N^{\prime}} v_{0 j k}^{s} & =\sum_{j \in N^{\prime}} v_{j 0 k}^{s} \quad \leq 1, \forall k \in K, \forall s \in S, \\
\sum_{i \in N} v_{i h k}^{s} & =\sum_{j \in N} v_{h j k}^{s}, \quad \forall h \in N^{\prime}, \forall k \in K, \forall s \in S .
\end{aligned}
$$

The constraint set (7) is used to eliminate tour loops.

$$
\sum_{i \in M} \sum_{j \in M} v_{i j k}^{s} \leq|M|-1, \quad \forall M \subset N^{\prime}, \forall k \in K, \forall s \in S \text {. }
$$

The constraint set (8) indicates the arrival time of the refrigerated vehicle $k$ at the customer $j$ in the scenario $s$.

$$
a_{j k}^{s}=l_{i k}^{s}+t_{i j k}^{s}, \quad \forall(i, j) \in G, \forall k \in K \forall s \in S .
$$

The constraint set (9) guarantees that the refrigerated vehicle $k$ should offer service for the customer $j$ within time windows in the scenario $s$.

$$
L_{j} \leq a_{j k}^{s}+w_{j k}^{s} \leq U_{j}, \quad \forall j \in N^{\prime}, \forall k \in K, \forall s \in S .
$$

The constraint set (10) indicates the leaving time of the refrigerated vehicle $k$ from the customer $j$ in the scenario $s$.

$$
a_{j k}^{s}+w_{j k}^{s}+f_{j k}=l_{j k}^{s}, \quad \forall j \in N^{\prime}, \forall k \in K, \forall s \in S .
$$

The constraint set (11) guarantees that the total products carried in the refrigerated vehicle $k$ cannot exceed its loading capacity in the scenario $s$. 
TABle 1: Sets.

\begin{tabular}{lc}
\hline Symbol & Meaning \\
\hline$N$ & The set of nodes, $N=\{0,1,2, \ldots, n\}$, where 0 indicates the cold chain logistics center. $N^{\prime}=N /\{0\}$ indicates the subset of \\
$G$ & customers. \\
$S$ & The set of paths, $G=\{(i, j): i \neq j, i \in N, j \in N\}$. \\
$K$ & The set of scenarios, $s \in S$. \\
$P$ & The set of refrigerated vehicles, $k \in K$. \\
The set of products' kinds, $p \in P$.
\end{tabular}

TABLE 2: Decision variables.

\begin{tabular}{lr}
\hline Symbol & Meaning \\
\hline$v_{i j k}^{s}$ & Whether transport products from $i$ to $j$ by $k$ under the scenario $s$. \\
$X_{j k p}^{s}$ & The number of $p$ products unloaded at $j\left(j \in N^{\prime}\right)$, which are transported by $k$ under the scenario $s$. \\
$H_{p}^{s}$ & The number of $p$ products that should be purchased under the scenario $s$. \\
$H^{s}$ & The number of vehicles that should be rented under the scenario $s$. \\
$w_{j k}^{s}$ & The waiting time of the vehicle $k$ at the customer $j\left(j \in N^{\prime}\right)$ under the scenario $s$. \\
\hline
\end{tabular}

Table 3: Parameters.

\begin{tabular}{|c|c|}
\hline Symbol & Meaning \\
\hline$D_{j p}^{s}$ & The number of $p$ products requested by $j$ under the scenario $s$, which is uncertain. \\
\hline$S_{p} P^{P}$ & The number of $p$ products that are available at the distribution center. \\
\hline$\stackrel{p}{V}$ & The number of available vehicles at the distribution center. \\
\hline$z_{k}$ & Carrying capacity. $z_{k}$ indicates how many products a vehicle can carry. \\
\hline$B, d_{i j}$ & transportation cost of a vehicle per kilometer. $d_{i j}$ is tl \\
\hline C & The fixed cost of using a vehicle. \\
\hline$U_{j p}^{s}, C_{j p}$ & $\begin{array}{r}U_{j p}^{s} \text { indicates whether meet the } j \text { 's }\left(j \in N^{\prime}\right) \text { demand for } p \text { under the scenario } s . C_{j p} \text { is the penalty cost of failing to fulfill or } \\
\text { exceeding the } j \text { 's }\left(j \in N^{\prime}\right) \text { demand for } p \text { under the scenario } s .\end{array}$ \\
\hline$R$ & The rental fee of a vehicle. \\
\hline$C_{P}$ & The price of $p$. \\
\hline$a_{j k}^{s}, l_{j k}^{s}$ & $\begin{array}{c}a_{j k}^{s} \text { is the time of the vehicle } k \text { arriving at the } j \text { under the scenario } s . l_{j k}^{s} \text { is the time of the vehicle } k \text { leaving the } j \text { under the } \\
\text { scenario } s \text {. }\end{array}$ \\
\hline $\begin{array}{l}t_{i j k}^{s} \\
f_{j k}\end{array}$ & $\begin{array}{c}\text { The travel time of the vehicle } k \text { from } i \text { to } j \text { under the scenario } s . t_{i j k}=d_{i j} / v_{k} \text {, where } v_{k} \text { is the speed of the vehicle } k \text {. } \\
\text { The service time of the vehicle } k \text { for the customer } j\left(j \in N^{\prime}\right)\end{array}$ \\
\hline$L_{j}, U_{j}$ & The time window of the customer $j\left(j \in N^{\prime}\right)$. \\
\hline$\beta_{i j k p}^{s}$ & The number of $p$ products carried in the vehicle $k$ from $i$ to $j$ under the scenario $s$. \\
\hline$w_{S}$ & The weights assigned to the scenario $s$. \\
\hline
\end{tabular}

$$
\sum_{j \in N^{\prime}} \sum_{\mathrm{p} \in P} \beta_{0 j k p}^{s} v_{0 j k}^{s} \leq z_{k}, \quad \forall k \in K, \forall s \in S .
$$

The constraint set (12) indicates whether demand is met or not. $U_{j p}^{s}=0$ means that demand is met in the scenario $s$. $U_{j p}^{s}<0$ means that the cold chain logistics center fails to fulfill demand in the scenario $s . U_{j p}^{s}>0$ means that the cold chain logistics center provides more products for $j$ than the demand in the scenario $s$.

$$
U_{j p}^{s}=\sum_{i \in N} \sum_{k \in K} v_{i j k}^{s} X_{j k p}^{s}-D_{j p}^{s}, \quad \forall j \in N^{\prime}, \forall p \in P, \forall s \in S .
$$

The constraint set (13) indicates how many products are in the refrigerated vehicle $k$ after it leaving $j$ in the scenario $s$.

$$
\sum_{i \in N} v_{i h k}^{s} \beta_{i h k p}^{s}-X_{h k p}^{s}=\sum_{j \in N} v_{h j k}^{s} \beta_{h j k p}^{s}, \quad \forall h \in N^{\prime}, \forall p \in P, \forall s \in S .
$$

In terms of the constraint set (14), the number of products transported from the cold chain logistics center to all customers cannot exceed its available products and the products that should be purchased in the scenario $s$. In other words, the cold chain logistics center should purchase products if the available products are not enough. 


$$
\sum_{j \in N^{\prime}} \sum_{k \in K} \beta_{0 j k p}^{s} \leq S_{P}+\mathrm{H}_{p}^{s}, \quad \forall p \in P, \forall s \in S .
$$

In terms of the constraint set (15), the number of vehicles that are used to transport products cannot exceed the available vehicles at the logistics center and the rented vehicles in the scenario $s$. In other words, the distribution center should rent vehicles if the available vehicles are not enough.

$$
\sum_{k \in K} \sum_{j \in N^{\prime}} v_{0 j k}^{s} \leq V+H^{s}, \quad \forall k \in K, \forall s \in S .
$$

The constraint sets (14) are congruity constraints, which ensure that the decision variables to be implemented are the same in each scenario.

$$
\begin{aligned}
v_{i j k}^{s 1} & =v_{i j k}^{s 2}=\cdots=v_{i j k}^{s n}, \quad \forall(i, j) \in G, \forall k \in K, \forall s \in S, \\
X_{j k p}^{s 1} & =X_{j k p}^{s 2}=\cdots=X_{j k p}^{s n}, \quad \forall j \in N^{\prime}, \forall k \in K, \forall p \in P, \forall s \in S, \\
H_{p}^{s 1} & =H_{p}^{s 2}=\cdots=H_{p}^{s n}, \quad \forall p \in P, \forall s \in S, \\
H^{s 1} & =H^{s 2}=\cdots=H^{s n}, \quad \forall s \in S, \\
w_{j k}^{s 1} & =w_{j k}^{s 2}=\cdots=w_{j k}^{s n}, j \in N^{\prime}, \forall \quad k \in K, \forall s \in S .
\end{aligned}
$$

The constraint set (15) indicates that $v_{i j k}^{s}$ are $0-1$ variables, and the other decision variables are nonnegative values.

$$
v_{i j k}^{s} \in\{0,1\}, X_{j k p}^{s} \geq 0 \mathrm{H}_{p}^{s} \geq 0, \mathrm{H}_{s} \geq 0, w_{j k}^{s} \geq 0 .
$$

3.2. Solution Method. The proposed multiscenario model has two objective functions. To tackle the model, we use the objective function set (22) in place of the objective function set (1). $\xi$ is the unitary time cost. According to the new objective function set, we aim to minimize the expected cost of delivery time rather than the expected delivery time.

$$
\min f \prime=\sum_{s \in S} w^{s}\left(\xi \sum_{i \in N} \sum_{j \in N} \sum_{k \in K} v_{i j k}^{s} t_{i j k}^{s}+\sum_{i \in N} \sum_{j \in N^{\prime}} \sum_{k \in K} v_{i j k}^{s} w_{j k}^{s}+\sum_{i \in N} \sum_{j \in N^{\prime}} \sum_{k \in K} v_{i j k}^{s} f_{j k}\right) .
$$

Then, the new multi-scenario optimization model can be represented as follows:

$$
\left\{\begin{aligned}
& \operatorname{minc}^{\prime}= \sum_{s \in S} w^{s}\left(\sum_{j \in N^{\prime}} \sum_{k \in K} C_{k} v_{0 j k}^{s}+\sum_{i \in N} \sum_{j \in N} \sum_{k \in K} B d_{i j} v_{i j k}^{s}+R H^{s}+\sum_{p \in P} C_{P} H_{P}^{s}+\sum_{j \in J^{\prime}} \sum_{p \in P} C_{j p}\left|U_{j p}^{s}\right|\right. \\
&\left.+\xi \sum_{i \in N} \sum_{j \in N} \sum_{k \in K} v_{i j k}^{s} t_{i j k}^{s}+\sum_{i \in N} \sum_{j \in N^{\prime}} \sum_{k \in K} v_{i j k}^{s} w_{j k}^{s}+\sum_{i \in N} \sum_{j \in N^{\prime}} \sum_{k \in K} v_{i j k}^{s} f_{j k}\right) \\
& \text { s.t } \quad(3)-(15)
\end{aligned}\right.
$$

\section{Empirical Study}

Inner Mongolia Shiquanshimei (Group) Co., Ltd., established in 2000 in China is a highly standardized, large-scale, and information-based company specialized in food circulation in Inner Mongolia. At present, the company has established eight wholesale markets in Hohhot, the capital of Inner Mongolia. These wholesale markets mainly engage in the wholesale and retail business of meat, fruits, vegetables, etc. The company has established a cold chain logistics center in southern Hohhot, which is responsible for delivering products to the eight markets. The locations of the eight 


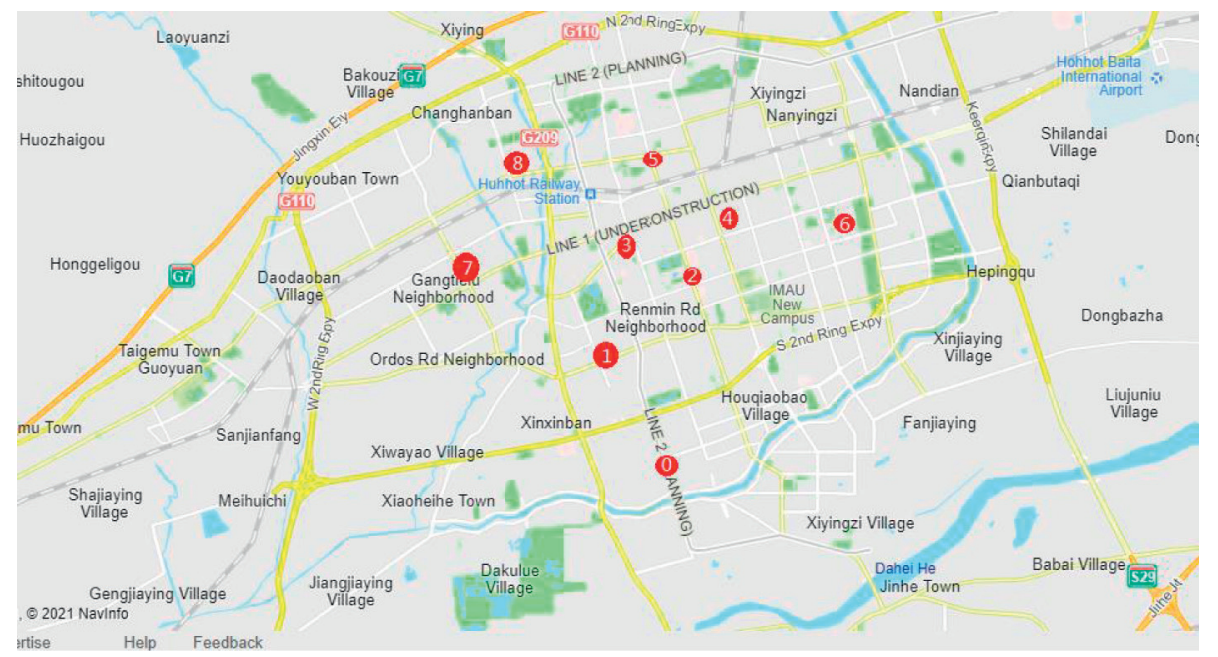

FIgURE 1: The locations of Shiquanshimei's wholesale eight markets and the cold chain logistics center.

wholesale markets and the cold chain logistics center are shown in Figure 1. The distance between any two points is shown in Table 4.

In the early days of the COVID-19 outbreak, the wholesale market demand dropped by $50 \%$ as a result of people's fear of virus infection. During that period, it was hard for the cold chain logistics center to deal with the dilemma of reduced demand. However, it is harder to cope with uncertain demand while the demand in the wholesale markets is changing drastically with the changes of the COVID-19 cases at present. When there is no case, demand is stable. In the early stage of the new cases reported, demand increases because people want to store food. After that, demand decreases as people go out less. Therefore, the cold chain logistics center urgently needs optimization methods for dealing with uncertain demand in emergency situations.

4.1. Data. At present, the cold chain logistics center owns four 5 -ton $(3.3 \mathrm{~m})$ refrigerated vehicles. The refrigerated vehicles' transportation cost, the fixed cost, and the rental fee are $0.5 \mathrm{CNY} / \mathrm{km}, 100 \mathrm{CNY}$, and $200 \mathrm{CNY}$, respectively. The speed of all refrigerated vehicles is $50 \mathrm{~km} / \mathrm{h}$. As stated above, the demand is uncertain because it is impossible to predict whether there will be new cases reported in advance. According to the method of scenario analysis, the uncertain demand for two commodities, i.e., kiwi and dragon fruit, is divided into three important scenarios. The demand for the two commodities in each scenario is shown in Table 5. The demand is decreased in Scenario 1, as expected in Scenario 2, and increased in Scenario 3. The time windows of the eight wholesale markets are shown in Table 6. The number of available kiwi and dragon fruit is 10 tons and 8 tons, respectively. The service time at each wholesale market is 15 minutes. The penalty cost of failing to fulfill or exceeding demand is $100 \mathrm{CNY} /$ ton. The prices of kiwi and dragon fruit are $5000 \mathrm{CNY} /$ ton and $1200 \mathrm{CNY} /$ ton, respectively. Refrigerated vehicles can be used to transport products from 5 : 00 a.m. to $11: 00$ a. m.
TABle 4: Distance (km).

\begin{tabular}{cccccccccc}
\hline & 0 & 1 & 2 & 3 & 4 & 5 & 6 & 7 & 8 \\
\hline 0 & - & 3 & 4.7 & 6 & 6.1 & 7.5 & 6.9 & 6.3 & 8 \\
1 & 3 & - & 2.6 & 3.3 & 3.9 & 4.8 & 5.8 & 3.7 & 5.1 \\
2 & 4.7 & 2.6 & - & 1.8 & 1.4 & 3 & 3.4 & 5.3 & 5.1 \\
3 & 6 & 3.3 & 1.8 & - & 1.3 & 1.5 & 4.2 & 4.3 & 3.6 \\
4 & 6.1 & 3.9 & 1.4 & 1.3 & - & 2.1 & 3.2 & 5.6 & 4.7 \\
5 & 7.5 & 4.8 & 3 & 1.5 & 2.1 & - & 4.8 & 5 & 3.1 \\
6 & 6.9 & 5.8 & 3.4 & 4.2 & 3.2 & 4.8 & - & 8.7 & 7.9 \\
7 & 6.3 & 3.7 & 5.3 & 4.3 & 5.6 & 5 & 8.7 & - & 3.3 \\
8 & 8 & 5.1 & 5.1 & 3.6 & 4.7 & 3.1 & 7.9 & 3.3 & - \\
\hline
\end{tabular}

4.2. Results and Analysis. Three cases are proposed to solve the problem. Lingo is used to tackle the multi-scenario optimization model because it can solve linear, nonlinear, integer optimization models efficiently [32].

Case 1. Set $w_{s 1}=0.4, w_{s 2}=0.4, w_{s 3}=0.2$. The optimal vehicle routing plan is shown in Figure 2. The total expected cost is $1069 \mathrm{CNY}$. The cold chain logistics center does not need to purchase kiwi or dragon fruit. Three refrigerated vehicles are used.

Case 2. Set $w_{s 1}=0.4, w_{s 2}=0.2, w_{s 3}=0.4$. The optimal vehicle routing plan is shown in Figure 3. The total expected cost is $1229 \mathrm{CNY}$. The cold chain logistics center does not need to purchase kiwi or dragon fruit. Three refrigerated vehicles are needed.

Case 3. Set $w_{s 1}=0.2, w_{s 2}=0.4, w_{s 3}=0.4$. The optimal vehicle routing plan is shown in Figure 4. The total expected cost is $1313 \mathrm{CNY}$. The cold chain logistics center does not need to purchase kiwi or dragon fruit. Four refrigerated vehicles are used.

The multi-scenario model is more effective than the traditional deterministic models. If we set $w_{s 1}=1, w_{s 2}=0, w_{s 3}=0$, the multi-scenario model would degenerate into a deterministic model with the data in scenario 1 (Benchmark 1). If we set $w_{s 1}=0, w_{s 2}=1, w_{s 3}=0$, 
TABle 5: Demand (tons).

\begin{tabular}{|c|c|c|c|c|c|c|}
\hline \multirow{2}{*}{ Wholesale market } & \multicolumn{3}{|c|}{ p1 (kiwi) } & \multicolumn{3}{|c|}{$p 2$ (dragon fruit) } \\
\hline & $s 1($ Scenario 1$)$ & $s 2($ Scenario 2$)$ & s3 (Scenario 3) & $s 1$ (Scenario 1) & $s 2$ (Scenario 2) & $s 3$ (Scenario 3) \\
\hline 1 & 0.2 & 0.4 & 1 & 0.8 & 0.9 & 2 \\
\hline 2 & 0.7 & 1.3 & 2 & 0.6 & 1.2 & 1.5 \\
\hline 3 & 0.9 & 1.3 & 2 & 0.7 & 1.3 & 2.5 \\
\hline 4 & 0.9 & 1.1 & 1.1 & 0.8 & 0.9 & 1 \\
\hline 5 & 0.8 & 1.2 & 1.7 & 0.2 & 0.7 & 1 \\
\hline 6 & 1.1 & 1.2 & 1.5 & 0.9 & 1.1 & 2 \\
\hline 7 & 0.8 & 1.1 & 1.8 & 0.1 & 0.2 & 0.5 \\
\hline 8 & 0.9 & 1.2 & 1.5 & 0.5 & 0.8 & 1 \\
\hline
\end{tabular}

TABLE 6: Time windows.

\begin{tabular}{lc}
\hline Wholesale market & Time window \\
\hline 1 & $6: 00$ a.m. $\sim$ 8:00 a.m. \\
2 & $7: 00$ a.m. $\sim$ 9:00 a.m. \\
3 & 7:00 a.m. $\sim$ 9:00 a.m. \\
4 & $7: 00$ a.m. $\sim$ 9:00 a.m. \\
5 & $6: 00$ a.m. $\sim$ 8:00 a.m. \\
6 & $6: 00$ a.m. $\sim$ 8:00 a.m. \\
7 & $7: 00$ a.m. $\sim 9: 00$ a.m. \\
8 & $7: 00$ a.m. $\sim 9: 00$ a.m. \\
\hline
\end{tabular}

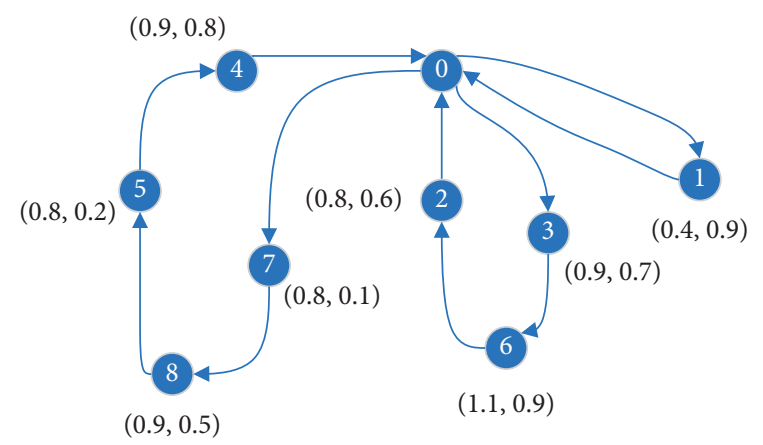

Figure 2: The optimal vehicle routing plan in Case 1.

the multi-scenario would degenerate into a deterministic model with the data in scenario 2 (Benchmark 2). If we set $w_{s 1}=0, w_{s 2}=0, w_{s 3}=1$, the multi-scenario model would degenerate into a deterministic model with the data in scenario 3 (Benchmark 3).

Benchmark 1: The optimal vehicle routing plan is shown in Figure 5. The total cost is $606 \mathrm{CNY}$. The cold chain logistics center does not need to purchase kiwi or dragon fruit. Three refrigerated vehicles are used.

Benchmark 2: The optimal vehicle routing plan is shown in Figure 6. The total cost is $746 \mathrm{CNY}$. The cold chain logistics center does not need to purchase kiwi or dragon fruit. Four refrigerated vehicles are used to transport.

Benchmark 3: The optimal vehicle routing plan is shown in Figure 7. The total cost is $18586 \mathrm{CNY}$. The cold chain logistics center should purchase 2.6 tons of kiwi and 3.5 tons of dragon fruit. Six refrigerated vehicles are needed so that the logistics center should rent two refrigerated vehicles.

As analyzed in Tables 7 and 8, the proposed multiscenario model is helpful for the cold chain logistics center to

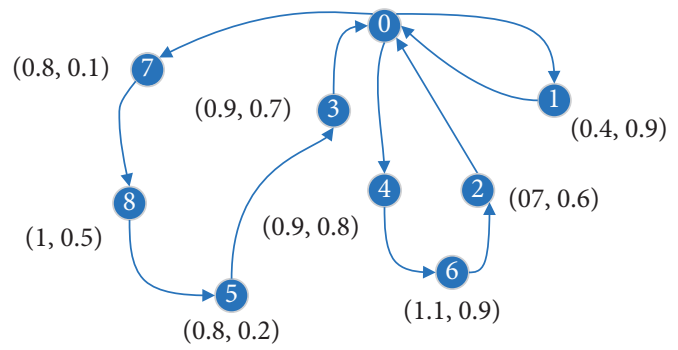

FIgURe 3: The optimal vehicle routing plan in Case 2.

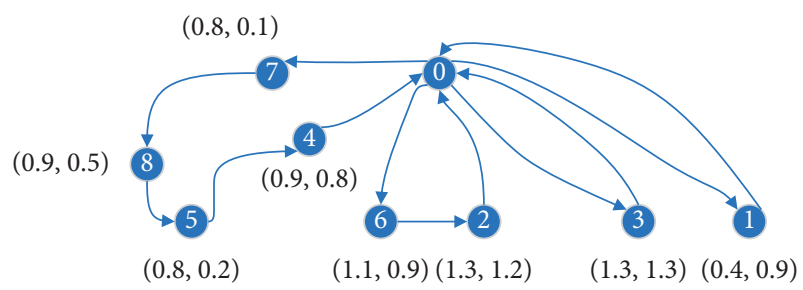

FIgUre 4: The optimal vehicle routing plan in Case 3.

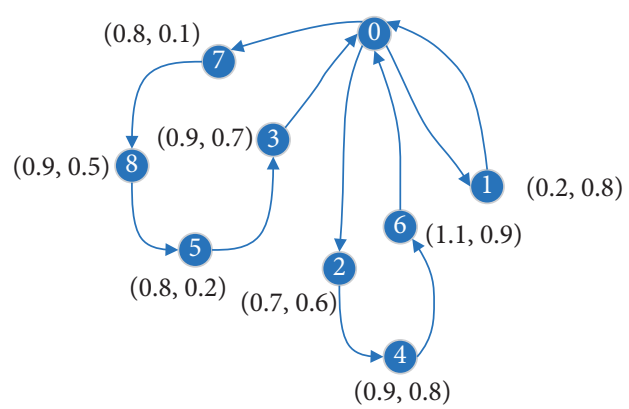

FIGURE 5: The optimal vehicle routing plan (Benchmark 1).

make an effective vehicle routing plan in response to the uncertainty of demand. The expected demand fulfillment in the three cases is $77.81 \%, 72.97 \%$, and $75.95 \%$, respectively. The expected total cost in the three cases is 1069 CNY, 1229 CNY, and 1313 CNY, respectively. All refrigerated vehicles visit customers within time windows. Although the demand fulfillment of Benchmark 2 and Benchmark 3 may be higher, the total cost would be as high as $19906 \mathrm{CNY}$. 


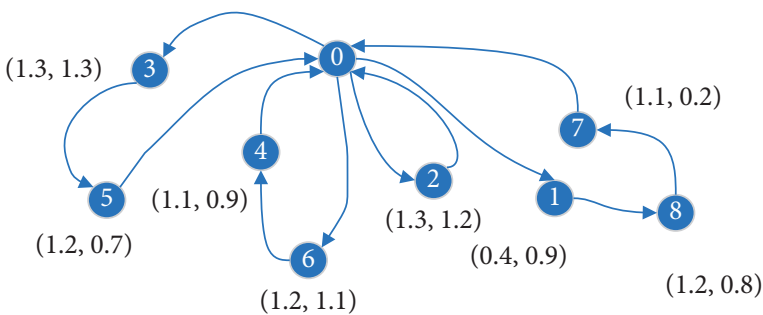

FIgURE 6: The optimal vehicle routing plan (Benchmark 2).

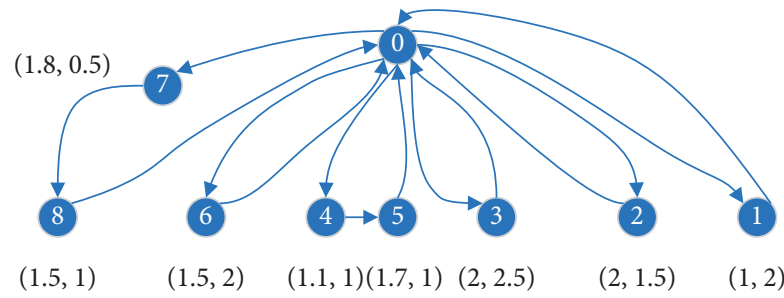

FIGURE 7: The optimal vehicle routing plan (Benchmark 3).

TABLE 7: Demand fulfillment.

\begin{tabular}{lccc}
\hline Case & $s 1$ realized (\%) & $s 2$ realized (\%) & $s 3$ realized (\%) \\
\hline Case 1 & 100 & 71.07 & 46.89 \\
Case 2 & 100 & 71.07 & 46.89 \\
Case 3 & 100 & 84.28 & 55.60 \\
Benchmark 1 & 100 & 68.56 & 45.23 \\
Benchmark 2 & 100 & 100 & 65.98 \\
Benchmark 3 & 100 & 100 & 100 \\
\hline
\end{tabular}

TABle 8: Total cost.

\begin{tabular}{lccc}
\hline Case & $\begin{array}{c}s 1 \text { realized } \\
(\mathrm{CNY})\end{array}$ & $\begin{array}{c}s 2 \text { realized } \\
(\mathrm{CNY})\end{array}$ & $\begin{array}{c}s 3 \text { realized } \\
(\mathrm{CNY})\end{array}$ \\
\hline Case 1 & 653 & 1073 & 1893 \\
Case 2 & 649 & 1069 & 1889 \\
Case 3 & 985 & 985 & 1805 \\
Benchmark 1 & 606 & 1106 & 1926 \\
Benchmark 2 & 1246 & 746 & 1566 \\
Benchmark 3 & 19906 & 19406 & 18586 \\
\hline
\end{tabular}

In summary, our multi-scenario model can help managers make an effective refrigerated vehicle routing plan against uncertainty in emergency situations and can degenerate into a deterministic model when the parameters are certain. Therefore, the validity of the model could be confirmed. There are two main factors that can affect the effectiveness of the multi-scenario model as follows: (1) whether the generated scenarios are in line with reality; (2) whether the weights assigned to the scenarios are reasonable. Managers should create a professional team to estimate the two factors.

\section{Conclusions}

Emergency cold chain logistics can provide stable and reliable quality assurance for temperature-sensitive products in emergency situations. Demand is uncertain in emergency situations so that the cold chain logistics companies must cope with uncertain demand.

The innovation of this paper is that, to the best of our knowledge, this is the first paper to provide the methods for the optimization of emergency cold chain logistics distribution considering uncertain demand. To deal with uncertain demand, a novel multi-scenario optimization model for emergency cold chain logistics distribution is developed by using scenario analysis. Many factors, e.g., uncertain demand, time windows, product procurement, and vehicle renting, are considered in the multi-scenario optimization model. Because reducing delivery time is important to reduce the wastages of perishable products, the objectives of this model are to minimize the total cost and shorten the delivery time simultaneously. The multi-scenario optimization model is used to optimize the emergency cold chain logistics distribution of a Chinese company named Inner Mongolia Shiquanshimei (Group) Co., Ltd., and the results show that the proposed model is effective.

Due to the fallout of COVID-19, the world has entered a period of turbulence. The approach proposed in this paper is of great practical value for cold chain logistics companies to deal with the current predicament effectively. In the proposed model, we not only consider the uncertain demand but also suppose the logistics service provider can rent vehicles or purchase products if there are not enough resources. Therefore, our model is more in line with the actual operation.

In the future, cold chain logistics companies should pay more attention to carbon emissions because the world is moving to a low-carbon economy. Thus, the optimization of emergency cold chain logistics distribution should consider reducing carbon emissions. Only three important scenarios are studied in the case study because the optimization of emergency cold chain logistics distribution is NP-hard. We will develop heuristic algorithms to solve realistic-size problems in the near future.

\section{Data Availability}

The research data used to support the findings of this study are available from the corresponding author upon request.

\section{Conflicts of Interest}

The authors declare that there are no conflicts of interest regarding the publication of this paper.

\section{Authors' Contributions}

Yile $\mathrm{Ba}$ and Jianwei Ren conceptualized the study; Yile $\mathrm{Ba}$ and Chenxi Feng performed data curation; Jianwei Ren was responsible for funding acquisition; Yile $\mathrm{Ba}$, Chenxi Feng, Wenpeng Jia, and Xin Liu developed the methodology; Chenxi Feng, Wenpeng Jia, and Xin Liu provided the software; Yile Ba, Chenxi Feng, and Wenpeng Jia wrote the original draft; Yile Ba, Wenpeng Jia, Xin Liu, and Jianwei Ren reviewed and edited the article. 


\section{Acknowledgments}

This research was funded by the National Natural Science Foundation of China (71862026).

\section{References}

[1] X. Huang, R. Xie, and L. Huang, "Real-time emergency management mode of cold chain logistics for agricultural products under the background of Internet," Journal of Intelligent and Fuzzy Systems, vol. 38, pp. 1-13, 2020.

[2] C. Zheng, B. Peng, and G. Wei, "Operational risk modeling for cold chain logistics system: a bayesian network approach," Kybernetes, vol. 50, no. 2, pp. 550-567, 2021.

[3] X. Li, Z. Wang, S. Gao, R. Hu, Q. Zhu, and L. Wang, "An intelligent context-aware management framework for cold chain logistics distribution," IEEE Transactions on Intelligent Transportation Systems, vol. 20, no. 12, pp. 4553-4566, 2019.

[4] "Cold chain market by application, temperature type, type, regionlobal forecast to 2025, “2021, https://www.reportlinker. com/p04674549/Cold-Chain-Market-by-Type-TemperatureType-Technology-Application-and-Region-Global-Forecastto.html.

[5] Cold Chain Global Market Report 2021: COVID-19 Growth and Change, Business Research Company, India, https:// finance.yahoo.com/news/cold-chain-global-market-report090100823.html, 2021).

[6] C. Qi and L. Hu, "Optimization of vehicle routing problem for emergency cold chain logistics based on minimum loss," Phys. Commun.vol. 40, pp. 1-7, 2020.

[7] M. Zhang and J. Qu, "Optimization of perishable goods cold chain distribution network based on improved genetic algorithm," Logistics Engineering Managent, vol. 37, pp. 139-142, 2015.

[8] S. Fan, D. Lou, and Y. Sun, "Research on vehicle distribution path optimization of fresh agricultural products cold-chain logistics," Storage Process, vol. 17, pp. 106-111, 2017.

[9] J. Li, P. Fu, X. Li, J. Zhang, and D. Zhu, "Study on vehicle routing problem and tabu search algorithm under low-carbon environment," Chineese Journal Managemant Science, vol. 23, pp. 98-106, 2015.

[10] Y. Pan, "Optimization model of cold chain logistics common distribution path for fresh agricultural products under the perspective of low carbon," Fresenius Environmental Bulletin, vol. 30, pp. 3445-3455, 2021.

[11] L. Liu, B. Su, and Y. Liu, "Distribution route optimization model based on multi-objective for food cold chain logistics from a low-carbon perspective," Fresenius Environmental Bulletin, vol. 30, pp. 1538-1549, 2021.

[12] X. Ma, T. Liu, P. Yang, and R. Jiang, "Vehicle routing optimization model of cold chain logistics based on stochastic demand," Journal of System Simulation, vol. 8, pp. 1824-1832, 2016.

[13] A. Osvald and L. Z. Stirn, "A vehicle routing algorithm for the distribution of fresh vegetables and similar perishable food," Journal of Food Engineering, vol. 85, no. 2, pp. 285-295, 2008.

[14] A. Zou and X. Luo, "Distribution model of emergency cold chain logistics under emergencies," Journal Changsha University, vol. 29, pp. 36-40, 2015.

[15] S. Wang, F. Tao, Y. Shi, and H. Wen, "Optimization of vehicle routing problem with time windows for cold chain logistics based on carbon tax," Sustainability, vol. 9, pp. 1-23, 2017.

[16] Y. Zhang, G. Hua, T. C. E. Cheng, and J. Zhang, "Cold chain distribution: how to deal with node and arc time windows?" Annals of Operations Research, vol. 291, no. 1-2, pp. 1127-1151, 2020.

[17] D. Nakandala, H. Lau, and J. Zhang, "Cost-optimization modelling for fresh food quality and transportation," Industrial Management \& Data Systems, vol. 116, no. 3, pp. 564-583, 2016.

[18] O. Theophilus, M. Dulebenets, J. Pasha, Y. Lau, A. FathollahiFard, and A. Mazaheri, "Truck scheduling optimization at a cold-chain cross-docking terminal with product perishability considerations," Computers \& Industrial Engineering, vol. 156, pp. 1-22, 2021.

[19] Y. P. Tsang, C. H. Wu, H. Y. Lam, K. L. Choy, and G. T. S. Ho, "Integrating Internet of Things and multi-temperature delivery planning for perishable food E-commerce logistics: a model and application," International Journal of Production Research, vol. 59, no. 5, pp. 1534-1556, 2021.

[20] M. Di Francesco, T. G. Crainic, and P. Zuddas, "The effect of multi-scenario policies on empty container repositioning," Transportation Research Part E: Logistics and Transportation Review, vol. 45, no. 5, pp. 758-770, 2009.

[21] B. He and L. Yin, "Prediction Modelling of cold chain logistics demand based on data mining algorithm," Mathematical Problems in Engineering, vol. 2021, Article ID 3421478, 9 pages, 2021.

[22] M. Wang, Y. Wang, W. . Liu et al., "How to achieve a win-win scenario between cost and customer satisfaction for cold chain logistics?” Physica A, vol. 566, pp. 1-11, 2021.

[23] J. Ren, B. Gao, J. Zhang, and C. Chen, "Measuring the energy and carbon emission efficiency of regional transportation systems in China: chance-constrained DEA models," Mathematical Problems in Engineering, vol. 2020, pp. 1-12, 2020.

[24] Y. Wu and Q. Song, "Improved particle swarm optimization algorithm in power system network reconfiguration," Mathematical Problems in Engineering, vol. 2021, Article ID 5574501, 10 pages, 2021.

[25] M. Di Francesco, M. Lai, and P. Zuddas, "Maritime repositioning of empty containers under uncertain port disruptions," Computers \& Industrial Engineering, vol. 64, no. 3, pp. 827-837, 2013.

[26] J. Ren, B. Liu, and Z. Wang, "An optimization model for multi-type pallet allocation over a pallet pool," Advances in Mechanical Engineering, vol. 9, pp. 1-9, 2017. 